JSACE $3 / 20$

From Ecological Architecture to Biomimicry

Received 2017/10/17 Accepted after revision $2017 / 11 / 13$

\section{From Ecological Architecture to Biomimicry}

\author{
Alex Mitxelena Etxeberria*, Enkarni Gomez Genua \\ ETS Arquitectura. University of the Basque Country (UPV/EHU) \\ *Corresponding author: alex.mitxelena@ehu.eus \\ $\Gamma$ \\ crossef http://dx.doi.org/10.5755/j01.sace.20.3.19295
}

\section{Introduction}

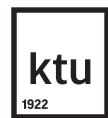

Journal of Sustainable Architecture and Civil Engineering Vol. 3 / No. 20 / 2017 pp. $68-74$

DOI 10.5755/j01.sace.20.3.19295 (c) Kaunas University of Technology
The economical development of industrialized countries is based on consumption of resources and worldwide pollution both unsustainable in the long and in the short term. But this model has entailed global warming, desertification of the planet, etc.

Being aware of this situation and the need of a rapid response (after the Second World War, or even before), environmental movements whose ideals were based on "environmental protection" arose. The question was to keep on growing, living, creating but damaging the environment the least possible. The terms "ecological" and "sustainable" emerged and theories and practices grew up with them.

The term ecological, however, does not necessarily mean sustainable. Sustainability doesn't only mean not damaging the environment but the possibility of maintaining the productive model in the long term. In principle, sustainability includes ecology by increasing its meaning. That is, what is not sustainable is not ecological. Thus, we could say that ideas of ecology and sustainability are complementary if not synonymous. Architecture, indeed, being responsible of much of the consumption of resources and pollutant emissions, cannot be left out of this paradigm. Architecture must also be ecological. This is one of the reasons why buildings are cataloged and certified for their degree of sustainability and energy efficiency. It is no longer ethical to turn away from the environment.

At the beginning of the 21 st century, a new paradigm emerges: biomimicry. This idea tries to go beyond respect for the environment, imitating the techniques and resources that nature itself offers us as solutions to problems.

This paper presents the way from the paradigm of ecology to the one of biomimicry applied to architecture, and proposes an architecture based on the principles of natural systems, according to a greater respect not only for the environment but also to favor a new balance between human beings and nature, and also among human beings themselves.

Keywords: architecture, biomimicry, ecology, natural systems.

The relationship of the human being with the surrounding environment is not simple, though, life depends on this relationship. The strategies used by the human being in relation to the environment have been different throughout history, starting from adaptation to domination. To dominate the environment has been an aspiration of the human being whose point of inflection can be placed in the scientific revolution of the $17^{\text {th }}$ century (Capra, 1982).

Understanding the world as a machine supposes a change, and the paradigm of domination of nature takes force in detriment of adaptation, and the exploitation of resources acquires a magnitude that over time and history proves itself unsustainable.

In this context, different social movements in the second half of the $20^{\text {th }}$ century position them- 
selves in front of the challenge of establishing a relationship with nature beyond the domination and exploitation of resources creating a new framework in which nature becomes an agent, not an object of domination nor a dominant entity. Thus emerges movements such as "Ecologism" and concepts such as "Sustainability".

The Organization of Ibero-American States and the website of its global action program publish "a renewed commitment to education for sustainability": "The concept of sustainability emerged in the early 1980s, based on scientific perspectives on the relationship between the environment and society and the publication of several relevant documents, notably the World Conservation Strategy (IUCN , 1980, First Global Strategy for Sustainable Development) and the Brundtland Report (Our Common Future, CMMAD, 1988). It arises as a result of analyzes of the world situation, which can be described as a "planetary emergency" (Bybee, 1991) and long-term (Orr, 2013), as an unsustainable situation, the result of human activities, which seriously threatens the future (and now the present) of humanity. There is even talk of a new geological stage, the anthropocene, a term proposed by Nobel laureate Paul Crutzen to highlight the responsibility of the human species in the profound changes that the planet is suffering (Sachs, 2008), linked to what Folke (2013) qualifies as "the Great Acceleration of human activity", especially since the 1950s, which threatens to exceed the limits of the planet."

The concept of biomimicry, on the other hand, proposes inspiration in nature as a way to improve the design of human creations. Biomimicry also implies an ecological commitment, since it understands that nature takes millennia developing models that are sustainable. Our intention here is to meditate on the way in which we can apply biomimicry for the definition of a sustainable and ecological architecture.

We interpret that there are two ways of approaching the biomimetic. The first is the imitation of the forms and structures of nature in a decontextualized way. Designing products with nature-inspired shapes is expected to help optimizing resources and improving outcomes, but this does not mean that they are more environmentally friendly or sustainable.

The second way of approaching the biomimetic is inspired by nature globally, in its cycles, in its way of using energy and resources. This will create an architecture that respects cycles and energy and also uses environmentally friendly or sustainable materials.

In this paper we want to propose some first ideas that can serve as inspiration to develop this paradigm of biomimetic architecture. We want to propose an architecture that takes into account the principles of natural systems defined by Benyus (1997) in a critical, ecological and sustainable way.

The proposed methodology consists of the application of the principles of natural systems to architecture and urban planning. This forms the basis of the ideation, the method of work and even the obtained results.

The principles of natural system are:

1. Nature runs on sunlight

2. Nature uses only the energy it needs

3. Nature fits form to function

4. Nature recycles everything

5. Nature rewards cooperation

The application of some of these principles will be immediate or easily solvable. Some other principles, however, will require a deeper reflection and will not find a simple application.
6. Nature banks on diversity

7. Nature demands local expertise

8. Nature curbs excesses from within

9. Nature taps the power of limits. 
Results and discussion

Nature runs on sunlight. The passive solar house proposes the use of sunlight to reduce the costs of heat production for the living spaces. In the same way, it proposes to close or isolate the parts that do not receive solar radiation and are, therefore, parts that lose the interior heat (AIA Research Corporation, 1978).

The organic architecture of the early twentieth century proposes another way to "take advantage" of sunlight: in addition to collecting solar radiation, it organizes the house according to the movement of the star. Architects like Frank Lloyd Wright or Hugo Häring explore the idea of the house that is organized according to the route of the sun throughout the day.

In the early 1920s, Hugo Häring began to develop housing according to a fluid and dynamic organization that adapted to the inhabitants' journeys and the sunlight (Blundell Jones, 1999). The rooms of these houses are not rectangular, their geometry is defined from the movements and the functional routes. Windows and interior spaces are organized to capture the sunlight. In addition, depending on the type of light we get from the sun, different throughout the day, different activities are developed.

The architect Rudolf Schindler (1934) built mid-20th century houses in Los Angeles with translucent roofs to recreate atmospheres in the rooms and join the interior spaces to the exterior.

We could consider as biomimetic architecture a solar house that modifies its space in relation to the sun. The sun, the cosmos and nature have a cyclical and eternal structure. A house illuminated according to solar cycles, making the inhabitant aware of the passage of time, of the seasons, reminding individuals of their belonging to the earth and the cosmos.

Nature uses only the energy it needs. We propose the approach to this point from the definition of needs, from which can be thought the energy required. That is, we must first know which with the needs and then have an idea of the energy that will need to be used. There are nine fundamental human needs classified by Artur Manfred Max Neef (1986):
1. Subsistence
4. Understanding
7. Creation
2. Protection
5. Participation
8. Identity
3. Affection
6. Leisure
9. Freedom

Needs such as subsistence, protection and affection can refer to the most private and intimate space. The design of housing in a conciliatory way offers spaces in which its inhabitants, in addition to satisfying the first two, do so taking into account affection as the axis of coexistence (Hayden, 1984).

Other needs are more related to urban design. For example, leisure and participation. Again, the gender perspective in urban design will guide us in the creation of a city in which leisure, housing and work are not separated, quite the contrary, we will look for ways that make possible the coexistence of these uses and allow easy access to citizens. In this way, in addition, will achieve a decrease in energy consumption.

The creation of these cities by means of participatory mechanisms will guarantee the satisfaction of the needs of understanding and participation, also creating the framework in which to fulfill creation, identity and freedom.

Measurement in the form of energy of these needs is certainly complex. However, we can understand that depending on the architecture and the city we build, we will consume more or less energy.

Cities and architectures will be more energy efficient, if the needs of all the people who inhabit are taken into account. If the projects are defined only for the most influential sectors, those groups that have not been considered will represent a higher energy expenditure. In this way, the overall calculation of energy expenditure will not be reduced. 
Nature fits form to function. The functions can be studied until determining their form, but this work will be conditioned according to the way in which we approach the definition of the problem. The analysis to define the functional kitchen performed in the 1920's in Germany resulted in a laboratory in which food preparation was developed very effectively (Muxi, 2015). However, it forgot the social aspect of this daily activity, proposing a kitchen that isolated the person who solved these functions.

Functions change with individual and social customs. A person does not perform the same tasks in adolescence, when he cares for his children or when he loses mobility in a punctual or permanent way. Also new social customs and needs arise.

The differentiation of spaces is a feature not as widespread in cultures as we can think. The psychologists Almerico and Pérez López (1998), describe the house "highly differentiated" as that in which each part fulfills a certain function and indicates its extension exclusively to the European and North American cultures.

Before the specialization of the domestic spaces we know, the medieval houses of our culture consisted of a single multifunctional space. The rooms were not specialized, the space of the home was one and, depending on the furniture used and its layout, different actions were carried out throughout the day and according to the needs of its inhabitants (Mitxelena, 2014).

The Japanese architect Sou Fujimoto (2008) proposes two antagonistic ways of responding to functional needs. As it describes, the house can be created according to the type "nest" or the type "cave". The "nest" type is formalized according to the expected needs. Therefore, each function has assigned a place. Thus, the resulting space is concrete and defined, adjusted to certain functions. The "cave" space, by contrast, materializes before defining the functions to be performed.

The proposals presented lead us to reflect on the creation of an architecture that responds in a specific way to specific functions. Without a doubt, it will be an architecture that will not be able to adapt to new needs and new users. Fujimoto's "nest space" is limited, since the inhabitant cannot modify his routines, improvise or change his customs. However, in the "cave space" the inhabitant can improvise, can change their customs, adapt the house to their needs, their changes. Instead of oppressing functions, the cave is a means of provocation without restrictions.

Nature recycles everything. Nature closes the cycles using debris as nutrients, so the falling leaves of the trees nourish the terrestrial substrate that feeds trees and other plants. The circular economy proposes to observe the cycles of nature to apply them to economic concepts for the sake of greater sustainability.

"Circular economy is an economic concept that is interrelated with sustainability, and whose objective is to keep the value of products, materials and resources (water, energy, ...) in the economy for as long as possible, and waste generation is minimized. It is about implementing a new economy, circular - not linear - based on the principle of "closing the life cycle" of products, services, waste, materials, water and energy (Economia..., 2017)."

Bringing this concept to architecture forces us to think of buildings or urban systems that recycle or reuse waste. This can be achieved in two different ways, on the one hand, we can create architecture that will not subsequently generate waste (once demolished for example) and can maximize the reuse of materials, in which case it is important to choose the materials and possibly their disposition; on the other, we can talk about buildings, or urban systems that recycle in the day to day. In this sense we could talk about circular economy systems, or circular cities whose first call for accession was made in Paris in December 2015, at the Climate Summit. Circular Cities Network was generated from them, with the objective of sharing experiences in this field.

We must think of an architecture that generates less waste and cities that also program the reuse of waste as energy generators and rethinking their uses. 
Reusing can also mean sharing. Spaces where objects and goods are shared. It also has to do with collaboration, cooperation and involves not only the reuse or recycling, but the reduction of consumption through sharing. For example, housing that fosters coexistence favors both the reduction and reuse or recycling of resources.

Nature rewards cooperation. Natural systems take care of future generations and reward cooperation, so biomimetic architecture must also be facilitative, conciliatory and reward the mutual help of the people who inhabit it.

The spaces of relation must be designed also thinking about the encounter, the interchange and the interaction of the people who inhabit them. Like nature, we need spaces in which to care for the community and which prioritize the well-being of people. In this way we will create an architecture thought from our way of life, but without forgetting the context of which we are part. Thus, it will be a sustainable architecture, from the point of view of energy and social, and also sustainable over time, properly managed.

The cohabitation co-housing model is formed by a community that is cohesive in its understanding of the relationship between private life and common life. It is made up of private dwellings and an important endowment of common services. It is planned and managed by its residents, according to the model they decide, allowing them to define the project according to their specific needs. Cohousing facilitates coexistence and cooperation among residents, as well as the centralization of facilities and services, providing social, economic and environmental benefits.

Nature banks on diversity. Modernist Architecture took to the extreme the idea of the city as a network of communication and movement. The concepts set forth in the Athens Charter in 1941 proposed a technical and aseptic approach to the territory. The ideas of functionalism had succeeded in eliminating all other possible interpretations of reality. However, after World War II, new generations of architects and architects understood that differences in places were a source of information to build environments adapted to the physical and cultural characteristics of each environment.

Again, applying the gender perspective in urban design will design cities in which different functions coexist, making them more accessible and in which interactivity will create more livable spaces. As described by Gea 21 (2007) "The mix of uses is key to the goal of conciliation. The segregated and specialized districts oblige to perform the different functions of life in remote spaces: to reside, to buy, to work, to have fun, etc."

In addition, nature is enriched by accumulation and also cities have been built over time and as a result of accumulation. For this reason, the public space is an example of accumulation and diversity, starting from the architecture that conforms it, to the actions and functions performed in it, as well as the inhabitants that move in it.

If in agriculture monoculture has harmful effects on ecosystems, in the spaces we build, monofunctionality also has similar effects. It loses diversity of uses and loses the wealth that only the mixture can create. Urbanism appears too often as a discipline separating functions, which does not favor social interaction. Monofunctionality thus impoverishes life, cultural diversity and the urban landscape.

Nature demands local expertise. Vernacular architecture is the result of its environment. It is characterized by its excellent features with the most elementary formulas. The discreet tradition of popular architecture has always tended to maintain a profitable and sensible relationship with its immediate natural environment. Here, too, the idea of the "sustainable" is perceived. The idea is to adapt to the environment and take from it what it offers to be able to build.

The vernacular architecture shows us that in places where there are trees columns are made with their trunks and lintels to be able to open the holes of the doors and to hold the covers. In tropical 
latitudes, lacustrine or flooded habitats appear palafitos, with enclosures and enclosures of leaves of local plaited plants. Where there is stone, it is used to stack and make walls, long before they have learned to carve it. However, where there is only soil and straw, adobes or bricks are made. Thus, the design of each construction is adapted to the specific climatic conditions of each place. The heat of North Africa is fought by the thermal properties of the adobe. In the tropics, braids and frameworks of lightweight structures allow permanent ventilation. The specific physiognomy of vernacular constructions is the result of an evolution similar to that of natural organisms. By means of the trial-error procedure and with the means provided by the environment, in an evolution of thousands of years the types that have been replicated indefinitely have been polished.

Although we consider that vernacular architecture is characterized by taking advantage of what is near, and building according to available materials around, we should be cautious in the proposal to continue building in the $21^{\text {st }}$ century as was done in the $17^{\text {th }}$, or $19^{\text {th }}$. At least as far as western societies are concerned. We must consider today that this sustainability depends basically also on the magnitude of the use of resources.

Nature curbs excesses from within. Society, and in particular the agents who direct society, regulates architecture. Nature benefits the system because it seeks to balance it, but when societies and their leaders generate systems that benefit a few to the detriment of others inequalities increase and balance is lost. When the nature loses the balance it exerts the control from within to recover it. This internal control system is called self-regulation. Self-regulated societies would therefore be societies whose internal control leads to greater balance.

Architecture as a social product depends on the groups in which it is created to be balanced and self-regulated. Thus, people, new architectural, neighborhood associations, collectivists, aware of the need for self-regulation, may be self-regulating, balanced in their excesses, in the use of materials and technology. For this, the educational proposals in the centers of architecture have to take into account the social responsibility of the professionals so that the discipline itself is a self-regulating agent.

Nature taps the power of limits. This last point is intimately linked to the previous one, as we have seen, nature is limited to itself, imposes internal limits that avoid excesses and encourage self-regulation. Thus, architecture must be limited to itself, from the same profession. The participation of users is also essential.

In addition to internal limits or self-regulation, nature takes advantage of external limits. Thus the skin marks the boundary between being and non-being. The human being grows aware of the exterior through the relation with the other. The outer limits also structure. They make reality understandable. Thus, the combination of internal and external boundaries is also desirable in architecture and urbanism.

The architecture and urban planning that center users, citizens and society as a whole contribute to regulation, structuring and defining the limits of what is built and how it is built. It is understood in this way that the limits are internal, the internal limits are always easier to respect than the external or normative limits, which are basically those that today limit architecture and urban planning.

The regulations are necessary to avoid excesses, however an excess of regulations can damage the architecture limiting the proposals and subtracting its creativity and imagination.

To realize architecture that fulfills all the conditions of the principles of the biomimicry is perhaps complicated, nevertheless we can approach to the biomimetic and sustainable architecture.

The vernacular architecture, without being biomimetic in itself, is perhaps among the forms of architecture that we know, which most fulfills the conditions of biomimicry. However, it should be adapted to current needs and reality; since the exploitation of nearby resources may not be sustainable today and it may be necessary to think about the use of other types of materials. 
Many of the stamps used to classify architecture from the point of view of ecology and sustainability are not appropriate from our point of view.

Biomimetic architecture understood as the imitation of the forms of nature, or the use of natural elements within the architecture is not sustainable either in itself.

The paradigm of biomimicry is a recent paradigm; whose development is unequal in the different disciplines to which it is being applied. From our point of view, the possibilities that it offers for the architecture are still to be explored in its totality. There are timid attempts at biomimetic architecture that are still partial. It would be necessary to be able to integrate the idea of biomimicry with ecology and sustainability.

\section{References}

AIA Research Corporation for the U.S. Dept. of Housing and Urban Development, Office of Policy Development and Research in Cooperation. Regional Guidelines for Building Passive Energy Conserving Homes. Washington: The GPO Office; 1978.

Amerigo M., Perez Lopez, R. Ambientes residenciales. In: Aragones J. I., Amerigo M. Psicología Ambiental. Madrid: Pirámide; 1998.

Benyus J. Biomimicry. Innovation inspired by nature. New York: Harper Collins; 1997.

Blundell Jones, P. Hugo Häring. The organic versus the geometric. Stuttgart: Axel Menges; 1999.

Capra F. El punto crucial. Ciencia, sociedad y cultura naciente. Barcelona: Ed. Integral; 1982.

Fujimoto S. Primitive future. Tokyo: INAX Publishing; 2008.

Gea 21. Viviendas que concilian. La perspectiva de género aplicada a las viviendas de nueva construcción. Madrid, Concejalía de Igualdad y Empleo.
Ayuntamiento de Fuenlabrada; 2007.

Hayden D. Redesigning the American dream: the future of housing, work and family life. New York: W. W. Norton, 1984.

Max Neef A. M. Desarrollo a escala humana: conceptos, aplicaciones y reflexiones. Barcelona: Icaria Editorial; 1986.

Mitxelena A. La esencia humana de la casa. Bilbao: UPV/EHU; 2014.

Muxi Z. Margarete Schütte-Lihotzky 1897-2000. Un día | una arquitecta. Consultado el 9 de julio de 2017. 2015.

Pawlyn M. Biomimicry in architecture. London: Riba Publishing; 2011.

Riechmann J. Biomímesis. Ensayo sobre imitación de la naturaleza. Ecosocialismo y autocontención. Madrid: Catarata; 2006.

Schindler R.M. Space architecture. Dune Forum, Oceans, California; 1934.

\section{About the authors}

\section{ALEX MITXELENA ETXEBERRIA \\ Lecturer and Vice Dean, Quality and Teaching Innovation \\ University of the Basque Country, School of Architecture, Department of Architecture}

\section{Main research area}

Architectural Design

\section{Address}

Oñati Plaza, 2

20018 Donostia - San Sebastian, Spain

Tel. +34943015482

E-mail: alex.mitxelena@ehu.eus

\section{ENKARNI GÓMEZ GENUA}

Lecturer and Vice Dean, International Relations, Mobility and Multilingualism

University of the Basque Country, School of Architecture, Department of Applied Physics II

\section{Main research area}

Architecture and Gender

\section{Address}

Oñati Plaza, 2

20018 Donostia - San Sebastian, Spain

Tel. +34943015887

E-mail: enkarni.gomez@ehu.eus 